\title{
Could the beneficial effects of dietary calcium on obesity and diabetes control be mediated by changes in intestinal microbiota and integrity?
}

\author{
J. M. G. Gomes ${ }^{1 *}$, J. A. Costa ${ }^{2}$ and R. C. Alfenas ${ }^{2}$ \\ ${ }^{1}$ Instituto Federal do Sudeste de Minas Gerais - Campus Barbacena, Rua Monsenbor José Augusto, 204, Bairro São José, \\ Barbacena, Minas Gerais CEP 36205-018, Brazil \\ ${ }^{2}$ Nutrition and Health Department, Federal University of Viçosa (Universidade Federal de Viçosa), Avenida PH Rolfs, s/n, \\ Viçosa, Minas Gerais CEP 36570-000, Brazil
}

(Submitted 14 May 2015 - Final revision received 3 August 2015 - Accepted 17 August 2015 - First published online 24 September 2015)

\section{Abstract}

Evidence from animal and human studies has associated gut microbiota, increased translocation of lipopolysaccharide (LPS) and reduced intestinal integrity (II) with the inflammatory state that occurs in obesity and type 2 diabetes mellitus (T2DM). Consumption of Ca may favour body weight reduction and glycaemic control, but its influence on II and gut microbiota is not well understood. Considering the impact of metabolic diseases on public health and the role of $\mathrm{Ca}$ on the pathophysiology of these diseases, this review critically discusses possible mechanisms by which high-Ca diets could affect gut microbiota and II. Published studies from 1993 to 2015 about this topic were searched and selected from Medline/PubMed, Scielo and Lilacs databases. High-Ca diets seem to favour the growth of lactobacilli, maintain II (especially in the colon), reduce translocation of LPS and regulate tight-junction gene expression. We conclude that dietary Ca might interfere with gut microbiota and II modulations and it can partly explain the effect of Ca on obesity and T2DM control. However, further research is required to define the supplementation period, the dose and the type of Ca supplement (milk or salt) required for more effective results. As Ca interacts with other components of the diet, these interactions must also be considered in future studies. We believe that more complex mechanisms involving extraintestinal disorders (hormones, cytokines and other biomarkers) also need to be studied.

\section{Key words: Calcium: Gut microbiota: Intestinal permeability: Endotoxin: Lipopolysaccharide}

$\mathrm{Ca}$ is the major mineral component of the skeletal system, and it is also an essential nutrient required for blood clotting, nerve conduction and muscle contraction, besides being essential for endocrine and hormone secretion ${ }^{(1)}$. In adults, adequate $\mathrm{Ca}$ intake, as recommended in the dietary reference intakes, seems to prevent obesity ${ }^{(2)}$ and type 2 diabetes mellitus (T2DM) ${ }^{(3)}$. Possible mechanisms involving $\mathrm{Ca}$ that may favour weight and glycaemic control are still not well understood. The results of in vitro and animal studies suggest that low-Ca diets increase calcitriol (1,25-dihydroxyvitamin D) and parathormone concentrations, resulting in $\mathrm{Ca}$ influx into adipocytes. Increased intracellular $\mathrm{Ca}^{2+}$ activates lipogenesis (mediated by fatty acid (FA) synthase) and suppresses lipolysis (hormone-sensitive lipase), increasing body fat and inducing insulin resistance (IR) ${ }^{(4)}$. Calcitriol also inhibits the expression of adipocyte uncoupling protein 2, reducing mitochondrial FA transport and lipid oxidation ${ }^{(4)}$. Another possible mechanism is the interaction between dietary $\mathrm{Ca}$ and FA in the gut, forming insoluble Ca FA soaps, which in turn increases faecal fat excretion and reduces dietary energy ${ }^{(5)}$.
Influx of $\mathrm{Ca}^{2+}$ into muscle cells promotes GLUT4 translocation and, hence, increases glucose uptake and insulin sensitivity in skeletal muscle ${ }^{(6)}$. A moderate influx of $\mathrm{Ca}$ into pancreatic $\beta$-cells is essential for converting proinsulin to insulin and promoting insulin release ${ }^{(7)}$. In healthy adults, Ca supplementation increased the concentrations of gastrointestinal insulinotropic hormones, especially glucose-dependent insulinotropic polypeptide and glucagon-like peptide-1 (GLP-1) ${ }^{(8)}$, and hence increased insulin sensitivity indirectly.

The beneficial effects of $\mathrm{Ca}$ ingestion could be associated with intestinal microbiota modulation and with increased integrity of the intestinal mucosa, as the results of human and animals' studies indicate the importance of these intestinal parameters on obesity and diabetes development ${ }^{(9-14)}$. Gut microbiota constitutes an important factor that affects nutrient absorption, energy homoeostasis, body weight control and $\mathrm{IR}^{(13)}$. Intestinal permeability can be defined as the property that allows solute and fluid exchange between the intestinal lumen and the tissues ${ }^{(15)}$. Gut barrier is a functional unit that prevents

Abbreviations: BA, bile acid; FA, fatty acid; FW, faecal water; GLP, glucagon-like peptide; II, intestinal integrity; LPS; lipopolysaccharide; T2DM, type 2 diabetes mellitus.

* Corresponding author: J. M. G. Gomes, fax +55 31389 92541, email junia.geraldo@ufv.br 
this exchange, composed of gut microbiota, mucus, polarised epithelial cell membrane, tight junctions and the innate and adaptive immune cells forming the gut-associated lymphoid tissue $^{(15-18)}$. Integrity of these barrier structures is essential to maintain normal intestinal permeability ${ }^{(18)}$. When the intestinal barrier is unimpaired, permeability is highly selective, avoiding the entrance of undesirable solutes, pathogenic microorganisms and toxins to the blood stream ${ }^{(16-18)}$. Integrity breakdown and increased intestinal permeability have been associated with obesity and diabetes aetiopathogenic mechanisms through the activation of proinflammatory pathways ${ }^{(9,12,19)}$.

In animal studies, increased intestinal permeability caused metabolic endotoxaemia (measured by the translocation of bacterial lipopolysaccharide (LPS) derived from gram-negative intestinal microbiota into the peripheral circulation), low-grade inflammation and glucose intolerance ${ }^{(9,20)}$. Studies have shown differences in gut microbiota composition and higher concentrations of circulating endotoxins when obese and/or diabetic subjects are compared with lean and normoglycaemic ones $^{(16,21-23)}$

Considering the low-Ca consumption by industrialised populations ${ }^{(24)}$ and the increase in the worldwide prevalence of obesity and T2DM, this review aims to discuss the influence of dietary $\mathrm{Ca}$ on gut microbiota composition and intestinal integrity (II) in order to elucidate a possible therapeutic strategy for the prevention and/or treatment of obesity and T2DM.

\section{Methods}

Medline/PubMed, Scielo and Lilacs were searched using the following terms: calcium, dairy food, gut or intestinal or gastrointestinal microbiota, gut or intestinal or gastrointestinal barrier, gut or intestinal or gastrointestinal permeability, lipopolysaccharide, endotoxins, metabolic endotoxemia, tight junction. For data searches, the terms in English, Spanish or Portuguese were used either alone or in association. Review and original studies published from 1993 to 2015 were selected according to their titles and abstracts. In vitro studies were excluded. Each selected manuscript was critically analysed.

\section{Gut microbiota and intestinal integrity: how might dietary calcium work?}

Human gut microbiome may be affected by short-term (about a few days) dietary Ca intake ${ }^{(25)}$. Dietary Ca may affect gut microbiota and II through mechanisms involving gastric acid secretion, bile acid (BA) and FA precipitation, competition among intestinal bacterial communities and changes on fermentation products in the colon and on intestinal mucosal integrity (Fig. 1). Online Supplementary Table S1 briefly describes studies that evaluated the effects of Ca supplementation on II in animals and humans.

Antimicrobial effect of gastric acid secretion. High-Ca diets $\left(30 \mathrm{mmol} \mathrm{Ca} / \mathrm{l}^{(26)}\right.$ and $\left.180 \mathrm{mmol} \mathrm{Ca} / \mathrm{kg} \mathrm{diet}^{(27)}\right)$ are associated with reduced number of viable bacteria in the stomach. A high intraluminal concentration of $\mathrm{Ca}^{2+}$ stimulates the release of gastrin and, consequently, increases acid secretion ${ }^{(28)}$. Several bacterial species (e.g. Salmonella) are destroyed by gastric

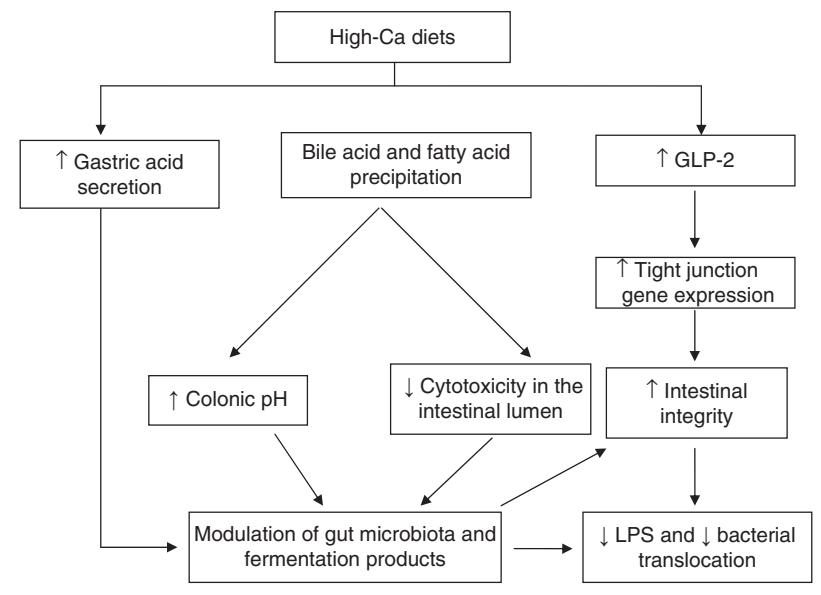

Fig. 1. Possible mechanisms explaining the effects of high-calcium diets on intestinal integrity and gut microbiota. High-calcium diets seem to change the intestinal environment through the following mechanisms: (1) increasing gastric secretion leading to increased gastric $\mathrm{pH}$ and reduced number of viable bacteria; (2) causing bile acid and fatty acid precipitation, increasing colonic $\mathrm{pH}$ and reducing cytotoxic components (especially NEFA and ionised secondary bile acids) that damage the epithelial cells; and (3) increasing glucagon-like peptide-2 (GLP-2) secretion, which has a trophic effect on intestinal mucosa and reduces gene expression of tight junctions (occludin and zonula occludens-1). These mechanisms may reduce bacterial and lipopolysaccharide (LPS) translocation, by bacterial fermentation and intestinal microbiota modulation, leading to a highly selective and controlled intestinal permeability.

acid $^{(29)}$. However, some factors, such as the buffering effect of food, gastric emptying rate and mechanisms of bacterial resistance, interfere with the interaction of gastric acid and ingested bacteria $^{(30)}$. Wistar rats ( $n 9$ per group) were fed ad libitum for $12 \mathrm{~d}$ a low-Ca diet (control: lactose-free low-Ca milk, $3.8 \%$ fat, $6 \mathrm{mmol} \mathrm{Ca} / \mathrm{l})$, regular lactose-free milk $(3.7 \%$ fat, $30 \mathrm{mmol}$ $\mathrm{Ca} / \mathrm{l}$ ), acidified milk or yoghurt (both prepared with regular lactose-free milk) ${ }^{(26)}$. These rats were orally infected with Salmonella enteritidis just after food consumption. Animals fed yoghurt had lower faecal excretion of bacteria than those in the other groups. The authors suggest that the lower gastric emptying rate after yoghurt consumption could have prolonged the exposure to gastric acid and, thus, reduced the effectiveness of the inoculation. Thereafter, faecal Salmonella excretion declined rapidly in all high-Ca groups compared with the control group ${ }^{(26)}$. Another study conducted by the same authors showed similar results ${ }^{(27)}$. Mice infected with $S$. enteritidis were fed high-, medium- or low-Ca diets ( $n 8$ per group; Ca in the form of $\mathrm{CaHPO}_{4}$ : 180, 60 and $20 \mathrm{mmol} / \mathrm{kg}$ diet, respectively). Compared with the low-Ca diet, the medium- and high-Ca diets favoured bacterial colonisation ${ }^{(27)}$. High-Ca intake $(30 \mathrm{mmol}$ $\mathrm{Ca} / \mathrm{l}^{(26)}$ and $180 \mathrm{mmol} \mathrm{Ca} / \mathrm{kg}$ diet $^{(27)}$ ) probably increased the gastric acidity and, hence, reduced viable counts of S. enteritidis ${ }^{(26,27)}$. Other studies also showed the antimicrobial effect of gastric $\operatorname{acid}^{(29,31)}$, which potentially modified the endogenous microbiota by reducing viable bacteria in the gut. In general, few microorganisms, such as Helicobacter pylori, some streptococci, lactobacilli and probiotics, can survive extremely acidic conditions within the stomach ${ }^{(32,33)}$. However, in some studies ${ }^{(26,27)}$, gastrin release and/or acid secretion were not measured. Therefore, we cannot conclude that the results of 
those studies ${ }^{(26,27)}$ were mediated by changes in gastric secretion. High protein content and the liquid state of the diets facilitated bacterial survival within the stomach ${ }^{(29)}$. Furthermore, some dairy product components, such as Ig, peptides, lactoferrin, lactoperoxidase and lysozyme, have antimicrobial effects. Other dairy components such as lactose, peptides and probiotics stimulate potentially beneficial bacteria that compete with pathogens for nutrients and attachment, and enhance the mucosal immune response to pathogens ${ }^{(34,35)}$.

Bile acid and fatty acid precipitation: reducing luminal cytotoxicity. Because of the low $\mathrm{pH}$, dietary $\mathrm{Ca}$ in the stomach exists in dissociated form, whereas in the small intestine there is an equilibrium between its dissociated and nondissociated forms. In the distal ileum and the colon, where $\mathrm{pH}>6$, Ca interacts with dietary phosphate, forming an insoluble complex that precipitates intestinal BA and FA. Hence, Ca increases their faecal excretion in animals ${ }^{(27,36-38)}$ and humans ${ }^{(39-44)}$. BA precipitation increases the de novo synthesis of BA from cholesterol in the liver and, hence, reduces serum cholesterol. FA precipitation reduces fat absorption, increasing faecal energy loss ${ }^{(5)}$.

Primary BA (cholic acid and chenodeoxycholic acid) are synthesised in the liver from cholesterol and then conjugated with either glycine or taurine, often called bile salts. About $5 \%$ of BA are deconjugated and dehydroxylated by bacterial enzymes in the intestine to form secondary BA (deoxycholic acid and lithocholic acid), which are more cytotoxic. The dehydroxylation process involves the removal of the $\mathrm{OH}$ group at the 7-position of the steroid nucleus (also termed 7-dehydroxylation). Deconjugation results in amino acid side chain cleavage. Among intestinal bacteria, 7-dehydroxylase was detected in the Eubacterium and Clostridium genera but not in lactobacilli and bifidobacteria ${ }^{(45,46)}$. BA hydrolysis is mediated by several gut microbiota genera, including Clostridium, Bacteroides, Lactobacillus, Bifidobacterium and Enterococcus ${ }^{(45)}$. Approximately $95 \%$ of BA are reabsorbed in the distal ileum and return to the liver (enterohepatic circulation of BA). About 400-800 mg BA/d elude enterohepatic circulation and are subjected to extensive modifications by the endogenous colonic microbiota. Secondary BA formed by colonic bacteria can be absorbed passively and, thus, may contribute to the BA pool ${ }^{(28)}$.

A small amount of NEFA and ionised secondary BA that reaches the colon can damage the intestinal epithelium and thus increase colonic permeability ${ }^{(47)}$. Therefore, BA and FA precipitation caused by dietary Ca promotes cytoprotective effects by reducing the bacteria's formation of cytotoxic surfactants. BA and FA precipitation ultimately maintains the integrity of the colonic epithelium.

Measuring the $\mathrm{BA}$ and FA concentrations in the soluble portion of the faeces (so-called faecal water $(\mathrm{FW})$ ) is more reflective of luminal cytotoxicity than measuring the total faecal BA and FA concentration ${ }^{(48)}$. FW refers to the supernatant obtained after intense centrifugation of the faeces. FW contains aqueous soluble BA and FA that are not linked to other faecal compounds ${ }^{(49)}$. In some studies, a high-Ca diet reduced the BA and FA concentration in $\mathrm{FW}^{(26,27,36-38,40,41)}$. A high-Ca diet also reduced FW cytotoxicity by precipitating cytotoxic surfactants, resulting in lower colonic epithelium damage and higher resistance to infections ${ }^{(26,27,36-38,40,41,47,50-52)}$. High-Ca diets contained $30 \mathrm{mmol} / \mathrm{l}^{(26)}, 225 \mu \mathrm{mol} / \mathrm{g} \mathrm{diet}^{(36,40)}, 120^{(47,51)}, 150^{(37)}$ or $180^{(27,38)} \mathrm{mmol} / \mathrm{kg}$ diet and $4.8 \mathrm{~g} / \mathrm{kg}$ diet $^{(52)}$ in the rats studies, and $1200 \mathrm{mg} / \mathrm{d}$ in the human study ${ }^{(41)}$. Some effects of cytotoxic surfactants are cell membrane disruption, inflammatory reaction activation and epithelium hyperproliferation enhancement ${ }^{(24,32,53)}$. Guarner ${ }^{(54)}$ criticised the use of erythrocytes instead of intestinal epithelial cells to analyse FW cytotoxicity, as done in some studies ${ }^{(26,27,36-38,40,41,47,50-52)}$. Erythrocytes are susceptible to changes in $\mathrm{pH}$ resulting from the production of SCFA after the fermentation of non-digestible carbohydrates. Therefore, haemolysis caused by changes in $\mathrm{pH}$ by SCFA may not reflect epitheliolysis ${ }^{(54)}$. On the other hand, intestinal cells normally use organic acids as an energy source $^{(54)}$. However, the erythrocyte assay has previously been validated $^{(49)}$. In a mouse study, the type of dietary fat influenced faecal FA excretion. Ca-PUFA soaps were more soluble and, therefore, better absorbed than Ca-saturated FA soaps ${ }^{(36)}$. The decreased absorption of intestinal fat (mainly saturated fat) caused by dietary $\mathrm{Ca}$ is of interest for the improvement of obesity control. By contrast, FA precipitation was independent of the source of $\mathrm{Ca}$ (milk, calcium carbonate or calcium phosphate) ${ }^{(37)}$ and dietary phosphate content (75, 125 or $275 \mathrm{mmol} / \mathrm{g}$ diet $)^{(40)}$.

Increased faecal fat excretion after Ca supplementation seems to favour weight control. An average daily intake of $1200 \mathrm{mg}$ of Ca results in the excretion of $5.2 \mathrm{~g}$ fat/ $\mathrm{d}$ and a weight loss of $2.2 \mathrm{~kg} /$ year $^{(55)}$. Therefore, it is possible that this mechanism contributes to obesity control but does not fully explain the effect of $\mathrm{Ca}$ on weight loss ${ }^{(5)}$. We believe that the impact of dietary Ca on weight loss is also related to dysbiosis attenuation. In this context, a high-Ca diet (>1100 mg/d) seems to modulate gut microbiota by reducing the number of BA and FA available for bacterial metabolism. It is possible that this effect increases Lactobacillus and reduces bile-tolerant bacteria, as discussed below.

Resistance to pathogens and changes in gut microbiota composition. In rodents, high-calcium phosphate diets increased faecal lactobacilli excretion ${ }^{(38,50,52)}$, reduced faecal Enterobacteriaceae excretion ${ }^{(50,56)}$ and increased resistance to $S$. enteritidis after $6-7 \mathrm{~d}$ of infection ${ }^{(38,50,52,56)}$. Ca concentrations of these diets were previously mentioned ${ }^{(38,52)}$, except the concentration adopted in the study conducted by Ten Bruggencate et al. ${ }^{(50,56)}$, which was $100 \mathrm{mmol} \mathrm{Ca} / \mathrm{kg}$ diet. Rats were fed diets with $60 \mathrm{~g} / \mathrm{kg}$ cellulose (control), fructooligosaccharides (FOS) or inulin with either a low $(30 \mathrm{mmol} / \mathrm{kg}$ ) or a high $(100 \mathrm{mmol} / \mathrm{kg}) \mathrm{Ca}$ concentration. After 2 weeks of adaptation, the animals were infected with $S$. enteritidis. During the following $6 \mathrm{~d}$, FW cytotoxicity increased in the rats on inulin and FOS diets, but the high-Ca diet minimised this adverse effect $^{(50)}$. In another study, rats infected with $S$. enteritidis were fed different sources of $\mathrm{Ca}$ supplements (calcium phosphate, milk Ca, calcium chloride or calcium carbonate (a total of

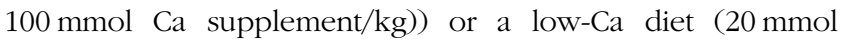
calcium phosphate $/ \mathrm{kg}$ ). After an adaptation period of 2 weeks, all the $\mathrm{Ca}$ supplements reduced infection and increased 
resistance to Salmonella ${ }^{(56)}$. Effects of Ca salts were similar to milk $\mathrm{Ca}^{(56)}$, suggesting a strategy to increase $\mathrm{Ca}$ intake in cases of restricted consumption of dairy foods - for example, lactose intolerance.

The authors suggest that the resistance to pathogens was because of BA and FA precipitation and, consequently, because of reduced cytotoxic surfactants in FW after calcium phosphate supplementation $^{(38,50,52,56)}$. However, only Bovee-Oudenhaven et $a l .{ }^{(38)}$ evaluated BA and FA faecal excretion. gram-negative bacteria (such as Escherichia coli and Salmonella spp.) are more bile-tolerant than gram-positive bacteria (such as some species of bifidobacteria, Bacillus, Lactobacillus and Enterococcus $)^{(45)}$. Therefore, the reduction in cytotoxicity in the intestinal lumen (reduction in the lytic activity of luminal surfactants), induced by dietary calcium phosphate, could improve the growth of Lactobacillus and other gram-positive bacteria compared with that of gram-negative bacteria.

Another mechanism by which dietary calcium phosphate interferes with resistance to pathogens is by binding directly to Salmonella and, hence, increasing the excretion of faecal bacteria, which is also known as bacterial shedding. This reduces pathogen competition and thus enhances the growth of lactobacilli. In vitro, ${ }^{(38,56)}$ but not vivo, ${ }^{(52)}$ studies confirmed this mechanism. In an in vivo study ${ }^{(52)}$, rats ( $n 8$ per group) infected with Salmonella were treated with an antibiotic and were either fed the control diet $(1.2 \mathrm{~g} / \mathrm{kg}$ diet $)$ or a high-Ca diet $(4.8 \mathrm{~g} / \mathrm{kg}$ diet). Both diets did not decrease Salmonella colonisation (measured by the excretion of faecal bacteria). The authors rejected the hypothesis that the binding of the calcium phosphate complex to Salmonella has a significant effect in vivo and, therefore, suggested that surfactant precipitation may increase endogenous microbiota.

Research on pigs showed different effects of calcium phosphate in intestinal lactobacilli colonisation. In general, high-calcium phosphate intake did not affect Lactobacillus spp. growth ${ }^{(57-59)}$ in the pigs' stomachs, ilea or colons. Only in the study by Mann et $a l^{(60)}$ did high- $v$. adequate-calcium phosphate diets increase Lactobacillus spp. growth in the stomach. These studies were performed with growing ${ }^{(57)}$ or weaned ${ }^{(58-60)}$ pigs ( $n 8$ per group) fed high-calcium phosphate diets: with an ileal pectin infusion ${ }^{(57)}$, with a high or low $\beta$-glucan content ${ }^{(58)}$, associated with a corn diet, or associated with a wheat-barley diet ${ }^{(59,60)}$. High-calcium phosphate diets contained $15 \mathrm{~g} \mathrm{Ca} / \mathrm{kg}$ diet $^{(50)}, 10 \mathrm{~g} \mathrm{Ca} / \mathrm{kg} \mathrm{diet}^{(51)}$ and $14.8 \mathrm{~g} \mathrm{Ca} / \mathrm{kg}$ diet $^{(59,60)}$. The main difference between these pig studies that explain the changes in gastrointestinal microbiota was the methodology used to quantify bacterial communities. Studies in which no effects on lactobacilli count were observed used quantitative $\mathrm{PCR}^{(57-59)}$, whereas Mann et al. ${ }^{(60)}$ used the pyrosequencing of $16 \mathrm{~S}$ rRNA genes. Because of the diversity and complexity of bacterial communities between species, the latter technique has been recommended. It has the capacity to sequence multiple fragments simultaneously and, thus, achieves more rapid and accurate bacterial genome sequences ${ }^{(59,61)}$. Although some authors criticise pyrosequencing for the phylogenetic classification of sequences obtained at the species level ${ }^{(61)}$, Mann et al. ${ }^{(60)}$ did not use it for pyrosequencing the total genome; rather, they only used it for the 16S rRNA gene. Thus, they demonstrated increases on operational taxonomic units for
Lactobacillus, indicating an increase in the number of microorganisms of this genus. This is extremely beneficial because of the effects of these bacteria on intestinal health.

Calcium phosphate diet modulated gastrointestinal microbiota in all pig studies, but the results were very different. Because of that, these studies will not be described in detail (see online Supplementary Table S1). In general, calcium phosphate intake over $14 \mathrm{~d}$ increased Clostridium cluster XI and XVIa in the ilea, caeca and colons of weaned pigs ${ }^{(57-60)}$. Several species of Clostridium cluster IV and XIVa produce butyrate, which is an important energy source for colonocytes ${ }^{(62)}$.

A double-blind, placebo-controlled, crossover study evaluated the composition of the gut microbiota after calcium phosphate and probiotic supplementation in humans ${ }^{(43)}$. Participants (thirtytwo healthy men and women aged 25 (SD 5) years and BMI of $22(\mathrm{sD} 3) \mathrm{kg} / \mathrm{m}^{2}$ ) consumed a probiotic drink containing $10^{10}$ colony-forming unit (CFU)/d Lactobacillus paracasei alone or in combination with bread containing calcium phosphate $(1 \mathrm{~g} / \mathrm{d})$ for 4 weeks. Calcium phosphate supplementation decreased total cholesterol, LDL-cholesterol and the LDL:HDL ratio, and increased faecal $\mathrm{pH}$ and the faecal excretion of secondary BA compared with supplementation with probiotics or placebo alone. Probiotic supplementation, alone or with calcium phosphate, increased faecal Lactobacillus excretion. The authors explained these effects as resulting from BA precipitation by amorphous calcium phosphate, particularly when BA are deconjugated by probiotics, and from the increased faecal excretion of these components. A less cytotoxic intestinal lumen, which contains a low concentration of cytotoxic surfactants, might favour the growth of lactobacilli and reduce blood cholesterol concentration because of the increased conversion of cholesterol into $\mathrm{BA}^{(43)}$.

The results of the studies with mice, pigs and humans are difficult to compare because of the diversity of micro-organism species in different hosts. Within the same species (mouse, pig or man), the intestinal maturation stage can also influence gut microbiota composition. For instance, Enterococcus spp. in the ileum were observed to decrease and increase in growing and weaned pigs, respectively, after calcium phosphate supplementation ${ }^{(57,59)}$. In humans, gut microbiota is dominated by bifidobacteria in the first 2-3 years of life (especially among breastfed children), remaining relatively stable in adults with $90 \%$ of the bacteria from the Bacteroidetes and Firmicutes phyla. In the elderly, gut microbiota becomes less diverse again (higher Bacteroides:Firmicutes ratio, an increase in Proteobacteria and a decrease in Bifidobacterium) ${ }^{(63)}$. Human gut microbiota also varies according to genetic background, diet, antibiotic use and the health status of the host ${ }^{(64)}$. Therefore, the interaction between $\mathrm{Ca}$ and other dietary nutrients (such as lactose, dietary fibre and probiotics) probably influences its effect on microbiota composition and activity.

Furthermore, the different results observed may be because of the variety of procedures used on microbiological analyses. These range from simple techniques such as counting $\mathrm{CFU}$ in mouse studies $^{(38,50,52)}$ to sophisticated molecular biology techniques such as quantitative PCR and pyrosequencing 16S rRNA genes in pig and human studies ${ }^{(43,57-60)}$. The variety in materials or parts of the gastrointestinal tract used to evaluate microbiota composition may also make comparisons difficult. Mouse and human studies 
used faeces ${ }^{(38,43,50,52)}$, whereas pig studies used different viscera (stomachs, small intestines, caeca and colons) ${ }^{(57-60)}$

Differences between BA in mice (predominantly taurineconjugated) and those in pigs (glycine-conjugated) also partly explain the diversity in results. In general, unconjugated BA and glycine-conjugated BA are more strongly precipitated by calcium phosphate than taurine-conjugated $\mathrm{BA}^{(38)}$. The taurineconjugated:glycine-conjugated BA ratio in human bile is usually $3: 1$, which is more similar to that in pigs than to that in rodents ${ }^{(45)}$.

Obesity is associated with changes in gut microbiota composition in animal and human research ${ }^{(10,65)}$. Some studies show an increase in the Firmicutes:Bacteroidetes ratio ${ }^{(66)}$, and others only show an overall decrease in Bacteroidetes and no change in Firmicutes $^{(22)}$. There are also differences between the gut microbiota of obese and lean subjects ${ }^{(65)}$. However, it is not yet clear whether obesity leads to dysbiosis or vice versa. If the effects of dietary $\mathrm{Ca}$ on lactobacilli growth are confirmed in human clinical trials, Ca supplementation will be a useful strategy in obesity treatment

Change in faecal $\mathrm{pH}$ and in fermentation products. Most mouse $^{(26,50,67)}$ and human ${ }^{(41,43)}$ studies have found an increase in faecal $\mathrm{pH}$ after high-Ca diets $\left(30 \mathrm{mmol} \mathrm{Ca} / \mathrm{l}^{(26)}, 100^{(50)}\right.$ and $120^{(67)} \mathrm{mmol} \mathrm{Ca} / \mathrm{kg}$ diet in mouse studies, and $1000^{(43)}$ or $1200 \mathrm{Ca} \mathrm{mg} / \mathrm{d}^{(41)}$ in human studies). Other mouse studies ${ }^{(36)}$, as well as pig studies ${ }^{(58,59)}$, did not reveal such differences, and only one study showed a decrease in faecal $\mathrm{pH}$ as a result of $\mathrm{Ca}$ supplementation $^{(37)}\left(225 \mu \mathrm{mol} \mathrm{Ca} / \mathrm{g}\right.$ diet $^{(36)}, 10^{(58)}$ or $14 \cdot 8^{(59)} \mathrm{g}$ $\mathrm{Ca} / \mathrm{kg}$ diet, and $\left.1 \mathrm{~g} / \mathrm{d}^{(37)}\right)$. The decrease in faecal $\mathrm{pH}$, caused by products of the colonic fermentation of non-digestible carbohydrates, supports the growth of beneficial bacteria (particularly bifidobacteria and lactobacilli) ${ }^{(68)}$. As previously mentioned, dietary $\mathrm{Ca}$ is soluble in acids, and it precipitates at alkaline $\mathrm{pH}$. Gastric acidity ( $\mathrm{pH} 1-3)$ is sufficient to release Ca complexed to salts or foods. Thus, the ionised $\mathrm{Ca}$ can be absorbed via transcellular active transport in the duodenum and proximal jejunum and via a passive paracellular process throughout the ileum. Less than $10 \%$ of $\mathrm{Ca}$ absorption occurs in the colon, and it involves the paracellular and transcellular pathways $^{(69)}$. About 25 to $35 \%$ of ingested $\mathrm{Ca}$ is generally absorbed. As $\mathrm{pH}$ increases from the ileum to the colon, the intestinal phosphate concentration also increases, causing $\mathrm{Ca}$ precipitation and $\mathrm{Ca}$ absorption reduction ${ }^{(28)}$. Therefore, an increase in $\mathrm{Ca}$ intake may increase the buffering capacity of faeces because of the formation of an amorphous calcium phosphate complex. In the studies discussed in our review, the acidification caused by bacterial fermentation may have been buffered by the high amounts of calcium phosphate in the colonic lumen (quantities described in the first paragraph of this session), causing no change or increase in faecal $\mathrm{pH}^{(26,36,41,43,50,58,67)}$. The buffering effect is suggested by the increase in the faecal excretion of $\mathrm{Ca}$ and phosphate ${ }^{(36,37,41,43)}$ and/or the decrease in BA and FA concentration in FW $^{(26,36,37,41,43)}$

In the animal research that evaluated the effect of Ca supplementation on the products of bacterial fermentation, there was an increase in acetate in the ilea ${ }^{(57)}$ and caproate in the colons ${ }^{(59)}$ of pigs. There was also an increase in lactate in the caeca ${ }^{(47)}$, and in propionate and butyrate in the faeces of mice $^{(70)}$. Metzler-Zebeli et al. ${ }^{(58)}$ observed a decrease in propionate in the caeca of pigs. The sources and quantities of fibre used to stimulate colonic fermentation varied among the studies (60 g pectin/ $\mathrm{d}^{(57)} ; 60 \mathrm{~g}$ FOS/kg diet ${ }^{(47)} ; 36 \mathrm{~g}$ crude fibre $/ \mathrm{kg} \mathrm{diet}{ }^{(59)} ; 6 \%(\mathrm{w} / \mathrm{w})$ galacto-oligosaccharides $\left.{ }^{(70)}\right)$. The use of probiotics in humans ${ }^{(71)}$ and animals ${ }^{(72)}$ increases $\mathrm{Ca}$ absorption, especially in the colon. However, even with this increase, it is possible that much of the ingested Ca transits through the colon without being absorbed ${ }^{(71)}$

In a crossover study, isoenergetic diets with similar macronutrient compositions, rich in semi-skimmed milk $(1.7 \mathrm{~g} \mathrm{Ca} / \mathrm{d})$ or cows' semihard cheese $(1.7 \mathrm{~g} \mathrm{Ca} / \mathrm{d})$, and ingested by fifteen healthy adult men over $14 \mathrm{~d}$ increased faecal SCFA (acetate, propionate and butyrate) in comparison with the control diet (which was rich in butter with approximately $360 \mathrm{mg} \mathrm{Ca/d}{ }^{(44)}$. In comparison with the control diet, both experimental diets increased faecal fat excretion, mainly in the milk group. Cheese intake resulted in higher faecal concentrations of propionate and butyrate, whereas milk intake promoted greater faecal excretion of acetate. These results indicate that milk and cheese stimulate bacterial activity differently. According to the authors, further studies are needed to explore the reasons for this difference. A possible interference factor is the protein profile of cheese (mainly casein, absorbed slowly) and of milk (20\% casein and $80 \%$ whey protein, with the latter absorbed faster) $^{(44)}$.

Colonic fermentation of fibre mainly generates lactate and SCFA. The amount and type of these metabolites formed depends on gut microbiota composition, the substrate and the intestinal transit time ${ }^{(73)}$. Acetate is produced by several groups of bacteria and comprises about 60 to $75 \%$ of total SCFA. In addition, acetate is metabolised in peripheral tissues (through the formation of acetyl-CoA) and/or used for butyrate synthesis ${ }^{(73)}$. The number of microorganisms that can produce propionate and butyrate is low. Propionate is mainly produced by Bacteroides spp., Clostridium cluster IX, Mitsuokella and Veillonella spp. ${ }^{(58)}$. Proprionate is metabolised in the liver via glycogenesis and is a lipolysis inhibitor and an inhibitor of the formation of acetyl-CoA from acetate ${ }^{(44)}$. Butyrate, an inhibitor of acetate synthesis, is the main energy source for colonocytes, followed by acetate and then propionate ${ }^{(44,74)}$. Some SCFA production, such as butyrate, is important not only as an energy source for colonocytes but it also prevents the accumulation of potentially toxic metabolites such as D-lactate. In addition, butyrate acts in visceral sensitivity and intestinal motility, regulates transcellular fluid transport, reinforces the gut barrier and reduces mucosal inflammation and oxidative stress ${ }^{(75)}$. Eubacterium rectale, Clostridium coccoides and Roseburia, which belong to the genus Clostridium cluster XIVa, are the largest butyrate producers ${ }^{(69)}$. Some species of Clostridium cluster XIVa can convert lactate to butyrate, whereas some cluster IX members can convert lactate to propionate ${ }^{(76)}$.

Lactic acid is a primary metabolite of fermentation in the caecum $^{(73)}$. The production of lactic acid and SCFA lowers the $\mathrm{pH}$, inhibiting the activity of microorganisms that metabolise lactate, for example, propionate-producing bacteria ${ }^{(77)}$. Excessive lactate production culminates in its accumulation in the 
colon as it has low intestinal absorption ${ }^{(76,77)}$. Overduin et al. ${ }^{(70)}$ suggest that dietary calcium phosphate supplementation influences this fermentation as the amorphous complex formed acts as a buffer against caecal acidification by lactate, thereby accelerating lactate conversion to SCFA in the caecum. According to the authors, colonocytes' rapid uptake of butyrate may have masked SCFA production, which explains why they observed lower concentrations of butyrate in the colons of rats that had been fed prebiotics. Moreover, as lactate is less absorbable, it can accumulate in the colon in larger quantities $^{(70)}$

Using the quantification of fermentation products to evaluate bacterial metabolic activity may be biased. Many of these products can act as intermediate substrates (i.e. lactate and acetate) and, therefore, may be associated with the metabolic activity of bacterial producers and/or bacterial users of these substrates. For example, an increase in lactate concentrations may indicate an increase in lactate producers or a decrease in lactate users. Therefore, it does not allow definitive conclusions. Moreover, about $95 \%$ of the SCFA produced by bacterial fermentation are absorbed by colonocytes during the intestinal transit. Therefore, a lack in the alteration of these components may not represent real changes in the gut microbiota. Perhaps it represents the more effective use of the components, mediated by $\operatorname{diet}^{(70,76,77)}$.

Obese subjects and animals have more SCFA in their caeca than lean ones. This seems to favour higher energy storage after the intake of non-digestible carbohydrate ${ }^{(66,78)}$ and lower intestinal transit time induced by the hormone peptide $\mathrm{YY}^{(79)}$. Overall, this favours weight gain. Although the effects of $\mathrm{Ca}$ have not been confirmed, considering the results of the studies analysed, it is possible that the increased faecal fat excretion and the modulation of gut microbiota that resulted from high-Ca diets (approximately1100 $\mathrm{mg} \mathrm{Ca} / \mathrm{d}$ in the human studies ${ }^{(41,43)}$ ) counteracted these effects.

Effects on intestinal permeability and integrity. Paracellular permeability allows substance movement between adjacent cells, by a passive process. In contrast, through transcellular permeability, transport can occur across the cells, and it involves both active and passive processes ${ }^{(17)}$. Several high-Ca salts (calcium phosphate, milk, calcium carbonate and calcium chloride) decreased intestinal permeability in rats $\left(100^{(56)}\right.$ or $120 \mathrm{mmol} \mathrm{Ca} / \mathrm{kg}^{(47,51,67,80)}$, and $\left.1.5 \% \mathrm{Ca}^{(81)}\right)$. Most of these studies used oral administration of EDTA chromium (Cr-EDTA) as a marker of intestinal paracellular permeability ${ }^{(47,51,67,80,81)}$. As Cr-EDTA is stable throughout the gastrointestinal tract, its excretion in the urine reflects total intestinal permeability ${ }^{(67)}$. Sugars, such as lactulose (reflecting paracellular permeability) and mannitol (transcellular permeability), are usually ingested to measure region-specific permeability. These sugars are readily degraded by colonic microbiota. Thus, the urinary excretion rate of these sugars (lactulose:mannitol ratio) is used to express the small intestine permeability ${ }^{(82)}$.

Compared with the control diet, high-Ca diets (quantities described in the previous paragraph) decreased Cr-EDTA urine excretion, and increased the lactulose:mannitol ratio in rats ${ }^{(67)}$.
However, there was no statistical difference when the urinary excretion of the lactulose and that of mannitol were analysed individually. On the basis of individual lactulose results, the authors concluded that dietary $\mathrm{Ca}$ did not affect the permeability of the small intestine. Consequently, they questioned the relevance of the lactulose:mannitol ratio and recommended measuring the excretion of each sugar individually ${ }^{(67)}$. This is relevant because, in some situations in which both sugars are excreted in large or small quantities, the ratio remains unchanged $^{(17)}$. Obese women appear to have higher urinary excretion of lactulose and mannitol, whereas their lactulose: mannitol ratio does not vary from that of lean women ${ }^{(83)}$. The use of large probes such as lactulose is the best way to analyse macromolecule passage through the intestinal barrier, such as dietary antigens and other components derived from bacteria $^{(17)}$. Another relevant example involves coeliac patients, who tend to have low mannitol excretion because of villous atrophy, whereas their lactulose excretion is high. When calculating the lactulose:mannitol ratio, this information does not lead to accurate results ${ }^{(84)}$. Therefore, it is suggested that $\mathrm{Ca}$ supplementation mainly affects colonic permeability ${ }^{(67)}$, which is expected, considering the previous discussion about the effects of $\mathrm{Ca}$ on BA and FA precipitation in the colon. This effect reduces cell damage and, consequently, increases the integrity of the epithelial mucosa.

In a transgenic animal model of colitis induction, $\mathrm{Ca}$ supplementation prevented colitis-induced increase in the expression of extracellular matrix remodelling genes such as matrix metalloproteinases, procollagens and fibronectin. This suggests that $\mathrm{Ca}$ strengthened the integrity of the colonic mucosa $^{(51)}$. Even in animal models, high dietary $\mathrm{Ca}(90 \mathrm{mmol} / \mathrm{kg})$ prevented the FOS-induced increase in intestinal permeability (measured by Cr-EDTA) only when phosphate content was medium ( $70 \mathrm{mmol} / \mathrm{kg}$ diet $)$ or high $(160 \mathrm{mmol} / \mathrm{kg} \mathrm{diet})$. This was not the case with low-phosphate diets $(5 \mathrm{mmol} / \mathrm{kg}$ diet $)$. The effect was attributed to the buffering capacity of the colonic lumen because of the formation of a calcium phosphate complex, which could reduce luminal cytotoxicity. In this respect, the phosphate content of the diet is not decisive, but it is necessary for the effect of $\mathrm{Ca}$ on intestinal permeability ${ }^{(47)}$. Therefore, based on Schepens et al. ${ }^{(47)}$, a ratio of about 1:1.3 of Ca:P can affect colon permeability.

Extracellular Ca (luminal Ca) was essential for intestinal tightjunction maintenance ${ }^{(85)}$. Tight junctions are apical intercellular joints, which contain transmembrane proteins, cytoskeleton components and cytoplasmic plaques ${ }^{(86)}$. These junctions act on cellular adhesion, intracellular signalling, protection against extracellular entrance and paracellular transportation of substances to the intestinal lumen ${ }^{(87)}$. Among the various tight-junction proteins, the transmembrane proteins (such as occludin and claudin) and cytoplasmic plaques (como a zonula occludens (ZO)) are important for paracellular transport ${ }^{(88)}$. Low-Ca and/or low-vitamin $\mathrm{D}$ diets reduce tight-junction gene expression in calbindin-null mice ${ }^{(88)}$, suggesting the importance of this mineral for the synthesis of tight-junction proteins and, therefore, for paracellular permeability. The intact microbiome appears to be essential for normal gut-brain axis signalling and the expression of calbindin, restoring the intrinsic and extrinsic 
enteric nerve function in germ-free mice, and causing changes to intracellular calbindin concentrations ${ }^{(89)}$. Thus, it is believed that the microbiome may contribute to improve dietary Ca absorption.

Calcium phosphate supplementation $(1 \mathrm{~g} / \mathrm{d})$ during 3 weeks increased GLP-1 and GLP-2 secretion in healthy adult men ( $n$ 10) in a double-blind placebo-controlled crossover study ${ }^{(8)}$. Trautvetter and Jahreis ${ }^{(8)}$ suggest that $\mathrm{Ca}$ supplementation stimulates the secretion of gastrointestinal hormones (GLP-1 and GLP-2) through the modulation of the intestinal environment. GLP-2 has trophic effects in the intestinal mucosa and influences the tightjunction gene expression (occludin and $\mathrm{ZO}-1)^{(90)}$. On the other hand, Metzler-Zebeli et al. ${ }^{(91)}$ observed a substantial downregulation of occludin and ZO-1 protein expression in the jejunum of weaned pigs ( $n 8$ per group) fed high-Ca diets $(14.8 \mathrm{~g} \mathrm{Ca} / \mathrm{kg}$ ) as compared with adequate-Ca diets $(8.2 \mathrm{~g} / \mathrm{kg})$, whereas gene expression in the colon was unaffected by dietary Ca concentration. The authors suggest that alterations in gene expression were not translated into functional protein, as they did not observe higher intestinal permeability, measured by an enhanced serum acute-phase response or intestinal translocation of $\operatorname{LPS}^{(59,91)}$.

LPS or serum anti-endotoxin antibodies, gut barrier disintegration and endotoxaemia markers were lower after high-Ca diets than after the control diet in mice ${ }^{(51,52)}$ (but not in pigs) ${ }^{(59)}$ $\left(120 \mathrm{mmol} \mathrm{Ca} / \mathrm{kg}^{(51)}, 4 \cdot 8^{(52)}\right.$ or $\left.14.8 \mathrm{~g} / \mathrm{kg} \operatorname{diet}^{(52)}\right)$. Moreover, $\mathrm{Ca}$ supplementation reduced bacterial translocation after Salmonella infection, indicating increased mucosal integrity $(27,38,50,52)$. However, we emphasise that differences in circulating endotoxin or bacteria may also reflect differences in detoxification or post-absorption clearance. Therefore, it is not related to intestinal translocation only ${ }^{(92,93)}$

Metabolic endotoxaemia, characterised by moderately elevated serum levels of LPS, is associated with obesity, T2DM and $\operatorname{IR}^{(10,20)}$. High-fat diets, which are generally associated with obesity, also seem to induce a reduction in II and low-grade endotoxaemia ${ }^{(94)}$. The factors involved in II breakdown in obese patients mainly consist of dysbiosis, adoption of dietary pattern characterised by foods rich in fat and fructose and deficiencies in the intake of nutrients ${ }^{(95)}$. In congruence with the mechanisms discussed in this review, we consider that the effects of Ca on II may involve gut microbiota and bacterial fermentation product modulation, in addition to direct action on tight junctions and a decrease in luminal cytotoxicity. For example, butyrate enhances the intestinal barrier because it facilitates the assembly of tight junctions ${ }^{(96)}$. It is possible that a high-Ca $(>1100 \mathrm{mg} / \mathrm{d}$ in the human studies selected for this review ${ }^{(41,43)}$ ) intake contributes to the maintenance of II, especially in the obese. However, because no human clinical trials have been conducted to date, it is not possible to confirm this association yet.

\section{Conclusions}

Dietary Ca appears to positively affect gut microbiota composition and II, which may improve obesity and T2DM treatment. The mechanisms suggested involve BA and FA precipitation and, consequently, a decrease in luminal cytotoxicity, lactobacilli growth and intestinal mucosal damage reduction. Ca appears to affect colon integrity to a great degree, and the amount of phosphate in the diet or the source of the $\mathrm{Ca}$ supplement appears to have minimal effect. PUFA faecal excretion seems to be lower than SFA excretion.

To our knowledge, the contribution of this modulation to the control of obesity and diabetes mellitus is uncertain. Further human clinical trials are needed to explore the potential of dietary $\mathrm{Ca}$ or $\mathrm{Ca}$ salt supplementation in the modulation of microbiota and intestinal barrier integrity and to ultimately determine the applicability of relatively simple dietary interventions to the treatment of chronic diseases. Further research is required to define the supplementation period, the dose and the type of $\mathrm{Ca}$ supplement (milk or salt) that is more effective in healthy, obese and diabetic subjects. As Ca interacts with other components of the diet, these interactions should also be considered in future research. We believe that more complex mechanisms involving extraintestinal disorders (hormones, cytokines and other biomarkers) also need to be studied.

\section{Acknowledgements}

The authors thank Coordenação de Aperfeiçoamento de Pessoal de Nível Superior (CAPES), Fundação de Amparo à Pesquisa do Estado de Minas Gerais (FAPEMIG) and Conselho Nacional de Desenvolvimento Científico e Tecnológico (CNPq).

This research received no specific grant from any funding agency, commercial or not-for-profit sectors.

The authors' contributions were as follows: J. M. G. G., J. A. C. and R. C. A. designed the concept of the study, and all authors were involved in the literature search and review. J. M. G. G. and J. A. C. wrote the manuscript. J. M. G. G., J. A. C. and R. C. A. were involved with editing the manuscript, and all authors read and approved the final manuscript.

None of the authors has any conflicts of interest to declare.

\section{Supplementary material}

For supplementary material/s referred to in this article, please visit http://dx.doi.org/doi:10.1017/S0007114515003608

\section{References}

1. Miller GD, Jarvis JK \& McBean LD (2001) The importance of meeting calcium needs with foods. I Am Coll Nutr 20, 168S-185S

2. Ferreira TS, Torres MRS \& Sanjuliani AF (2013) Dietary calcium intake is associated with adiposity, metabolic profile, inflammatory state and blood pressure, but not with erythrocyte intracellular calcium and endothelial function in healthy pre-menopausal women. Br J Nutr 110, 1079-1088.

3. Pittas AG, Lau J, Hu FB, et al. (2007) The role of vitamin D and calcium in type 2 diabetes. A systematic review and metaanalysis. J Clin Endocrinol Metab 92, 2017-2029.

4. Zemel MB, Shi H, Greer B, et al. (2000) Regulation of adiposity by dietary calcium. FASEB J 14, 1132-1138.

5. Jacobsen R, Lorenzen J, Toubro S, et al. (2005) Effect of shortterm high dietary calcium intake on 24-h energy expenditure, fat oxidation, and fecal fat excretion. Int J Obes 29, 292-301.

6. Youn JH, Gulve EA \& Holloszy JO (1991) Calcium stimulates glucose transport in skeletal muscle by a pathway independent of contraction. Am J Cell Physiol 260, C555-C561. 
7. Gilon P, Chae HY, Rutter GA, et al. (2014) Calcium signaling in pancreatic $\beta$-cells in health and in type 2 diabetes. Cell Calcium 56, 340-361.

8. Trautvetter U \& Jahreis G (2014) Effect of supplementary calcium phosphate on plasma gastrointestinal hormones in a double-blind, placebo-controlled, cross-over human study. Br J Nutr 111, 287-293.

9. Cani PD, Bibiloni R, Knauf C, et al. (2008) Changes in gut microbiota control metabolic endotoxemia-induced inflammation in high-fat diet-induced obesity and diabetes in mice. Diabetes 57, 1470-1481.

10. Cani PD, Possemiers S, Van de Wiele T, et al. (2009) Changes in gut microbiota control inflammation in obese mice through a mechanism involving GLP-2-driven improvement of gut permeability. Gut 58, 1091-1103.

11. Larsen N, Vogensen FK, van den Berg FW, et al. (2010) Gut microbiota in human adults with type 2 diabetes differs from non-diabetic adults. PLoS One 5, e9085.

12. Wu X, Ma C, Han L, et al. (2010) Molecular characterisation of the faecal microbiota in patients with type II diabetes. Curr Microbiol 61, 69-78.

13. Frazier TH, DiBaise JK \& McClain CJ (2011) Gut microbiota, intestinal permeability, obesity-induced inflammation, and liver injury. J Parenter Enteral Nutr 35, 14S-20S.

14. Moreno-Indias I, Cardona F, Tinahones FJ, et al. (2014) Impact of the gut microbiota on the development of obesity and type 2 diabetes mellitus. Front Microbiol 5, 190.

15. Odenwald MA \& Turner JR (2013) Intestinal permeability defects: is it time to treat? Clin Gastroenterol Hepatol 11, 1075-1083.

16. Natividad JM \& Verdu EF (2013) Modulation of intestinal barrier by intestinal microbiota: pathological and therapeutic implications. Pharmacol Res 69, 42-51.

17. Teixeira TFS, Moreira APB, Silva NCS, et al. (2014) Intestinal permeability measurements: general aspects and possible pitfalls. Nutr Hosp 29, 269-281.

18. Lopetuso LR, Scaldaferri F, Bruno G, et al. (2015) The therapeutic management of gut barrier leaking: the emerging role for mucosal barrier protectors. Eur Rev Med Pharmacol Sci 19, $1068-1076$.

19. Musso G, Gambino R \& Cassader M (2010) Obesity, diabetes, and gut microbiota: the hygiene hypothesis expanded? Diabetes Care 33, 2277-2284.

20. Cani PD, Amar J, Iglesias MA, et al. (2007) Metabolic endotoxemia initiates obesity and insulin resistance. Diabetes $\mathbf{5 6}$, $1761-1772$.

21. Ley RE, Turnbaugh PJ, Klein S, et al. (2006) Microbial ecology: human gut microbes associated with obesity. Nature $\mathbf{4 4 4}$, 1022-1023.

22. Turnbaugh PJ, Hamady M, Yatsunenko T, et al. (2009) A core gut microbiome in obese and lean twins. Nature $\mathbf{4 5 7}$, 480-484.

23. Jayashree B, Bibin YS, Prabhu D, et al. (2014) Increased circulatory levels of lipopolysaccharide (LPS) and zonulin signify novel biomarkers of proinflammation in patients with type 2 diabetes. Mol Cell Biochem 388, 203-210.

24. Imamura F, Micha R, Khatibzadeh S, et al. (2015) Dietary quality among men and women in 187 countries in 1990 and 2010: a systematic assessment. Lancet Glob Health 3 , e132-e142.

25. David LA, Maurice CF, Carmody RN, et al. (2014) Diet rapidly and reproducibly alters the human gut microbiome. Nature 505, 559-563.

26. Bovee-Oudenhoven I, Termont D, Dekker R, et al. (1996) Calcium in milk and fermentation by yoghurt bacteria increase the resistance of rats to Salmonella infection. Gut 38, 59-65.
27. Bovee-Oudenhoven IM, Termont DS, Weerkamp AH, et al. (1997) Dietary calcium inhibits the intestinal colonization and translocation of Salmonella in rats. Gastroenterology 113, 550-557.

28. Kopic S \& Geibel JP (2013) Gastric acid, calcium absorption, and their impact on bone health. Physiol Rev 93, 189-268.

29. Álvarez-Ordóñez A, Begley M, Prieto M, et al. (2011) Salmonella spp. survival strategies within the host gastrointestinal tract. Microbiology 157, 3268-3281.

30. Sarker SA \& Gyr K (1992) Non-immunological defence mechanisms of the gut. Gut 33, 987-993.

31. Zhu H, Hart CA \& Sales D (2006) Bacterial killing in gastric juice - effect of $\mathrm{pH}$ and pepsin on Escherichia coli and Helicobacter pylori. J Med Microbiol 55, 1265-1270.

32. Berg RD (1996) The indigenous gastrointestinal microflora. Trends Microbiol 4, 430-435.

33. Dicksved J, Lindberg M, Rosenquist M, et al. (2009) Molecular characterization of the stomach microbiota in patients with gastric cancer and in controls. J Med Microbiol 58, 509-516.

34. Mills S, Ross RP, Hill C, et al. (2011) Milk intelligence: mining milk for bioactive substances associated with human health. Int Dairy J 21, e401.

35. Venema K (2012) Intestinal fermentation of lactose and prebiotic lactose derivatives, including human milk oligosaccharides. Int Dairy J 22, 123-140.

36. Lapré JA, De Vries HT, Koeman JH, et al. (1993) The antiproliferative effect of dietary calcium on colonic epithelium is mediated by luminal surfactants and dependent on the type of dietary fat. Cancer Res 53, 784-789.

37. Govers MJ, Termont DS \& Van der Meer R (1994) Mechanism of the antiproliferative effect of milk mineral and other calcium supplements on colonic epithelium. Cancer Res 54, 95-100.

38. Bovee-Oudenhoven IMJ, Wissink MLG, Wouters JTM, et al. (1999) Dietary calcium phosphate stimulates intestinal lactobacilli and decreases the severity of a Salmonella infection in rats. J Nutr 129, 607-612.

39. Van der Meer R, Welberg JWM, Kuipers F, et al. (1990) Effects of supplemental dietary calcium on the intestinal association of calcium, phosphate, and bile acids. Gastroenterology 99 , $1653-1659$

40. Govers MJ \& Van der Meer R (1993) Effects of dietary calcium and phosphate on the intestinal interactions between calcium, phosphate, fatty acids, and bile acids. Gut 34, 365-370.

41. Govers MJAP, Termont DSML, Lapre' JA, et al. (1996) Calcium in milk products precipitates intestinal fatty acids and secondary bile acids and thus inhibits colonic cytotoxicity in humans. Cancer Res 56, 3270-3275.

42. Ditscheid B, Keller S \& Jahreis G (2009) Faecal steroid excretion in humans is affected by calcium supplementation and shows gender-specific differences. Eur J Nutr 48, 22-30.

43. Trautvetter U, Ditscheid B, Kiehntopf M, et al. (2012) A combination of calcium phosphate and probiotics beneficially influences intestinal lactobacilli and cholesterol metabolism in humans. Clin Nutr 31, 230-237.

44. Zheng H, Yde CC, Clausen MR, et al. (2015) Metabolomics investigation to shed light on cheese as a possible piece in the French paradox puzzle. J Agric Food Chem 63, 2830-2839.

45. Begley M, Gahan CG \& Hill C (2005) The interaction between bacteria and bile. FEMS Microbiol Rev 29, 625-651.

46. Floch MH (2002) Bile salts, intestinal microbiota and enterohepatic circulation. Digest Liver Dis 34, S54e7.

47. Schepens MA, ten Bruggencate SJ, Schonewille AJ, et al. (2012) The protective effect of supplemental calcium on colonic permeability depends on a calcium phosphateinduced increase in luminal buffering capacity. Br J Nutr 107, 950-956. 
48. Roberton AM (1993) Roles of endogenous substances and bacteria in colorectal cancer. Mutation Res 290, 71-78.

49. Lapré JA, Termont DS, Groen AK, et al. (1992) Lytic effects of mixed micelles of fatty acids and bile acids. Am J Physiol. 263 , G333-G337.

50. Ten Bruggencate SJ, Bovee-Oudenhoven IM, Lettink-Wissink ML, et al. (2004) Dietary fructo-oligosaccharides and inulin decrease resistance of rats to Salmonella: protective role of calcium. Gut 53, 530-535.

51. Schepens MA, Schonewille AJ, Vink C, et al. (2009) Supplemental calcium attenuates the colitis-related increase in diarrhea, intestinal permeability, and extracellular matrix breakdown in HLA-B27 transgenic rats. $J$ Nutr 139, $1525-1533$.

52. Van Ampting MT, Schonewille AJ, Vink C, et al. (2010) Damage to the intestinal epithelial barrier by antibiotic pretreatment of Salmonella-infected rats is lessened by dietary calcium or tannic acid. J Nutr 140, 2167-2172.

53. Ajouz H, Mukherji D \& Shamseddine A (2014) Secondary bile acids: an underrecognized cause of colon cancer. World J Surg Oncol 12, 164.

54. Guarner F (2007) Studies with inulin-type fructans on intestinal infections, permeability, and inflammation. J Nutr $\mathbf{1 3 7}$, 2568S-2571S

55. Christensen R, Lorenzen JK, Svith CR, et al. (2009) Effect of calcium from dairy and dietary supplements on faecal fat excretion: a meta-analysis of randomized controlled trials. Obes Rev 10, 475-486.

56. Ten Bruggencate SJ, Snel J, Schoterman MH, et al. (2011) Efficacy of various dietary calcium salts to improve intestinal resistance to Salmonella infection in rats. Br J Nutr $\mathbf{1 0 5}$, 489-495.

57. Metzler-Zebeli BU, Vahjen W, Baumgärtel T, et al. (2010) Ileal microbiota of growing pigs fed different dietary calcium phosphate levels and phytase content and subjected to ileal pectin infusion. J Anim Sci 88, 147-158.

58. Metzler-Zebeli BU, Zijlstra RT, Mosenthin R, et al. (2011) Dietary calcium phosphate content and oat $\beta$-glucan influence gastrointestinal microbiota, butyrate-producing bacteria and butyrate fermentation in weaned pigs. FEMS Microbiol Ecol 75, 402-413.

59. Metzler-Zebeli BU, Mann E, Schmitz-Esser S, et al. (2013) Changing dietary calcium-phosphorus level and cereal source selectively alters abundance of bacteria and metabolites in the upper gastrointestinal tracts of weaned pigs. Appl Environ Microbiol 79, 7264-7272.

60. Mann E, Schmitz-Esser S, Zebeli Q, et al. (2014) Mucosaassociated bacterial microbiome of the gastrointestinal tract of weaned pigs and dynamics linked to dietary calciumphosphorus. PLOS ONE 9, e86950.

61. Kim SW, Suda W, Kim S, et al. (2013) Robustness of gut microbiota of healthy adults in response to probiotic intervention revealed by high-throughput pyrosequencing. DNA Res 20, 241-253.

62. Louis P \& Flint HJ (2009) Diversity, metabolism and microbial ecology of butyrate-producing bacteria from the human large intestine. FEMS Microbiol Lett 294, 1-8.

63. Ottman N, Smidt H, de Vos WM, et al. (2012) The function of our microbiota: who is out there and what do they do? Front Cell Infect Microbiol 2, 104.

64. Nicholson JK, Holmes E, Kinross J, et al. (2012) Host-gut microbiota metabolic interactions. Science 336, 1262-1267.

65. Ridaura VK, Faith JJ, Rey FE, et al. (2013) Gut microbiota from twins discordant for obesity modulate metabolism in mice. Science 341, 1241214.
66. Ley RE (2010) Obesity and the human microbiome. Curr Opin Gastroenterol 26, 5-11.

67. Schepens MA, Rijnierse A, Schonewille AJ, et al. (2010) Dietary calcium decreases but short-chain fructo-oligosaccharides increase colonic permeability in rats. Br J Nutr 104, 1780-1786.

68. Fooks LJ \& Gibson GR (2002) Probiotics as modulators of the gut flora. Br J Nutr 88, S39-S49.

69. Bronner F (2009) Recent developments in intestinal calcium absorption. Nutr Rev 67, 109-113.

70. Overduin J, Schoterman MH, Calame W, et al. (2013) Dietary galacto-oligosaccharides and calcium: effects on energy intake, fat-pad weight and satiety-related, gastrointestinal hormones in rats. Br J Nutr 109, 1338-1348.

71. Whisner CM, Martin BR, Schoterman MH, et al. (2013) Galacto-oligosaccharides increase calcium absorption and gut bifidobacteria in young girls: a double-blind cross-over trial. Br J Nutr 110, 1292-1303.

72. Weaver CM, Martin BR, Nakatsu CH, et al. (2011) Galactooligosaccharides improve mineral absorption and bone properties in growing rats through gut fermentation. $J$ Agric Food Chem 59, 6501-6510.

73. Van Langen MAC \& Dieleman LA (2009) Prebiotics in chronic intestinal inflammation. Inflamm Bowel Dis 15, 454-462.

74. Pryde SE, Duncan SH, Hold GL, et al. (2002) The microbiology of butyrate formation in the human colon. FEMS Microbiol Lett 217, 133-139.

75. Canani RB, Costanzo MD, Leone L, et al. (2011) Potential beneficial effects of butyrate in intestinal and extraintestinal diseases. World J Gastroenterol 17, 1519-1528.

76. Louis P, Scott KP, Duncan SH, et al. (2007) Understanding the effects of diet on bacterial metabolism in the large intestine. J Appl Microbiol 102, 1197-1208.

77. Duncan SH, Louis P \& Flint HJ (2007) Cultivable bacterial diversity from the human colon. Lett Appl Microbiol 44, 343-350.

78. Schwiertz A, Taras D, Schafer K, et al. (2010) Microbiota and SCFA in lean and overweight healthy subjects. Obesity $\mathbf{1 8}$, 190-195.

79. Musso G, Gambino R \& Cassader M (2011) Interactions between gut microbiota and host metabolism predisposing to obesity and diabetes. Annu Rev Med 62, 361-380.

80. Schepens MA, Vink C, Schonewille AJ, et al. (2011) Supplemental antioxidants do not ameliorate colitis development in HLA-B27 transgenic rats despite extremely low glutathione levels in colonic mucosa. Inflamm Bowel Dis 17, 2065-2075.

81. Rao JP (2009) Influence of dietary calcium content on intestinal permeability in rat. Indian J Med Res 129, 681-684.

82. Arrieta MC, Bistritz L \& Meddings JB (2006) Alterations in intestinal permeability. Gut 55, 1512-1520.

83. Teixeira TFS, Souza NCS, Chiarello PG, et al. (2012) Intestinal permeability parameters in obese patients are correlated with metabolic syndrome risk factors. Clin Nutr 31, 735-740.

84. Vilela EG, Torres HOG, Ferrari MLA, et al. (2008) Gut permeability to lactulose and mannitol differs in treated Crohn's disease and celiac disease patients and healthy subjects. Braz J Med Biol Res 41, 1105e9.

85. Gonzalez-Mariscal L, Contreras RG, Bolivar JJ, et al. (1990) Role of calcium in tight junction formationbetween epithelial cells. Am J Physiol 259, C978-C986.

86. Gumbiner BM (1996) Cell adhesion: The molecular basis of tissue architecture and morphogenesis. Cell 84, 345-357.

87. Farquhar MG \& Palade GE (1963) Junctional complexes in various epithelia. J Cell Biol 17, 375-412.

88. Hwang I, Yang H, Kang HS, et al. (2013) Alteration of tight junction gene expression by calcium- and vitamin D-deficient diet in the duodenum of calbindin-null mice. Int J Mol Sci $\mathbf{1 4}$, 22997-23010. 
89. McVey Neufeld KA, Perez-Burgos A, Mao YK, et al. (2015) The gut microbiome restores intrinsic and extrinsic nerve function in germ-free mice accompanied by changes in calbindin. Neurogastroenterol Motil 27, 12534.

90. Dong CX, Zhao W, Solomon C, et al. (2014) The intestinal epithelial insulin-like growth factor-1 receptor links glucagonlike peptide- 2 action to gut barrier function. Endocrinology 155, 370-379.

91. Metzler-Zebeli BU, Mann E, Ertl R, et al. (2015) Dietary calcium concentration and cereals differentially affect mineral balance and tight junction proteins expression in jejunum of weaned pigs. Br J Nutr 113, 1019-1031.

92. Creely SJ, McTernan PG, Kusminski CM, et al. (2007) Lipopolysaccharide activates an innate immune system response in human adipose tissue in obesity and type 2 diabetes. Am J Physiol Endocrinol Metab 292, E740-E747.

93. Moreira AP, Texeira TF, Ferreira AB, et al. (2012) Influence of a high-fat diet on gut microbiota, intestinal permeability and metabolic endotoxaemia. Br J Nutr 108, 801-809.

94. Mani V, Hollis JH \& Gabler NK (2013) Dietary oil composition differentially modulates intestinal endotoxin transport and postprandial endotoxemia. Nutr Metab 10, 6.

95. Teixeira TF, Collado MC, Ferreira CL, et al. (2012) Potential mechanisms for the emerging link between obesity and increased intestinal permeability. Nutr Res 32, 637-647.

96. Ulluwishewa D, Anderson RC, McNabb WC, et al. (2011) Regulation of tight junction permeability by intestinal bacteria and dietary components. $J$ Nutr 141, 769-776. 